\title{
Precipitation Processes in the Beta-Titanium Alloy Ti-5Al-5Mo-5V-3Cr
}

\author{
James Coakley, ${ }^{\mathrm{a}, \mathrm{b}, *}$, Vasilli A Vorontsov ${ }^{\mathrm{c}}$, Nicholas G Jones ${ }^{\mathrm{a}}$, Anna Radecka ${ }^{\mathrm{c}}$, Paul AJ Bagot ${ }^{\mathrm{d}}$, Kenneth C Littrelle, \\ Richard K Heenan ${ }^{\mathrm{f}}$, Frédéric $\mathrm{Hu}^{\mathrm{c}}$, Andrew P Magyars, David C Bellg, David Dye ${ }^{\mathrm{c}}$ \\ ${ }^{a}$ Department of Materials Science and Metallurgy, University of Cambridge, Cambridge CB3 OF3, England \\ ${ }^{b}$ Department of Materials Science and Engineering, Northwestern University, 2220 Campus Drive, Evanston, IL 60208-3108, USA \\ ${ }^{c}$ Department of Materials, Imperial College London, South Kensington, London SW7 2AZ, England \\ ${ }^{d}$ Department of Materials, University of Oxford, Oxford OX1 3PH, England \\ ${ }^{e}$ Oak Ridge National Laboratory, Chemical and Engineering Materials Division, Oak Ridge, TN 37831 USA \\ ${ }^{f}$ Rutherford Appleton Laboratory, Didcot, Oxon OX11 0QX, England \\ ${ }^{g}$ School of Engineering and Applied Sciences, Harvard University, Cambridge, MA, USA
}

\begin{abstract}
Precipitate evolution in Ti-5Al-5Mo-5V-3Cr-0.3Fe wt.\% (Ti-5553) has been studied in-situ by small angle neutron scattering (SANS) during a two step ageing heat treatment of $300{ }^{\circ} \mathrm{C} / 8 \mathrm{~h}+500{ }^{\circ} \mathrm{C} / 2 \mathrm{~h}$. The first heat treatment step precipitates $\omega$, with a corresponding increase in hardness of $\sim 15 \%$ compared to quenched material. The second heat treatment step precipitates fine scale $\alpha$ from the $\omega$ phase, with a $\sim 90 \%$ increase in hardness compared to quenched material.

The SANS measurements are complemented by atom probe tomography (APT) to give compositional information, ex-situ transmission electron microscopy (TEM) to confirm phase identification and size distribution locally, and X-ray diffraction (XRD) for additional confirmation of phase identification.

The $\omega$ phase is depleted in all the solute additions following $300{ }^{\circ} \mathrm{C} / 8 \mathrm{~h}$ ageing heat treatment. The volume fraction of the $\omega$ phase from APT is estimated to be $\sim 7 \%$. SANS modelling is consistent with disc shaped particles for the $\omega$ phase. The mean particle diameter increases from $\sim 7.5 \mathrm{~nm}$ to $9.5 \mathrm{~nm}$ diameter between $1 \mathrm{~h}$ and $8 \mathrm{~h}$ heat treatment at $300^{\circ} \mathrm{C}$, while the thickness increases from $\sim 4 \mathrm{~nm}$ to $\sim 5 \mathrm{~nm}$. The SANS model estimates the volume fraction to be $\sim 10 \%$ for the $8 \mathrm{~h}$ heat treatment, using the phase compositions from APT.
\end{abstract}

Key words: Precipitation, titanium alloys, atom probe tomography (APT), transmission electron microscopy (TEM), small angle neutron scattering (SANS)

\section{Introduction}

Metastable $\beta$-Ti alloys are being increasingly employed ${ }_{20}^{19}$ in the aero-industry due to their extraordinary mechanical properties, namely a high strength to weight ratio and a good combination of toughness and fatigue resistance [1]. ${ }_{23}^{22}$ Ti-5Al-5Mo-5V-3Cr-0.3Fe wt.\% (Ti-5553) is a recent $\beta$-Ti ${ }_{24}$ alloy employed in large section forgings in the Boeing $787_{25}^{24}$ airframe [2].

Metastable $\beta$-Ti alloys are composed of a body-centered ${ }^{26}$ cubic (BCC) $\beta$ matrix and hexagonal closed-packed (HCP) ${ }_{28}^{27}$ $\alpha$ particles in their stable state. These alloys generally ${ }_{29}$ lack nucleation sites for $\alpha$, which combined with the high ${ }_{30}^{29}$ concentration of slow-diffusing solutes such as Mo, means ${ }_{31}^{30}$ that fully retained $\beta$ microstructures can be realised. Like many of the $\beta$-Ti alloys, Ti-5553 forms a metastable $\omega_{33}$ phase when quenched from above the $\beta$ transus $[3,4]$. This ${ }_{34}$ is referred to as athermal $\omega$ phase $\left(\omega_{\text {ath }}\right)$. Subsequent low ${ }_{35}^{34}$

${ }^{*}$ Corresponding Author. Tel: +1 312774 8634; fax: +1 $847467{ }^{37}$ 2269 ley)

Email address: james.coakley@northwestern.edu (James Coak- ${ }_{39}$ temperature ageing below approximately $450{ }^{\circ} \mathrm{C}$ completes the formation of the hexagonal $\omega$ phase and it is generally stated that the element distribution evolves from the parent BCC $\beta$ phase due to diffusion. This $\omega$ is distinguished as isothermal $\omega\left(\omega_{\text {iso }}\right)$ [5]. Ti alloys that are lean in $\beta$ stabilising elements may form a martensitic $\alpha^{\prime}$ or $\alpha^{\prime \prime}$ phase on quenching [6].

The high strength of $\beta$-Ti alloys is realised by the precipitation of fine $\alpha$ laths, on the order of $20 \mathrm{~nm}$ in width $[7,8]$. The micron size primary $\alpha$ produced during conventional $\alpha+\beta$ forging does not contribute substantially to strength, but does act to pin $\beta$ grain boundaries and prevent recrystallisation [9]. There is therefore a thread of work (e.g. $[10,11])$ that aims to engineer the $\alpha$ nanostructure by using $\omega_{\text {ath }}$ as a metastable precursor to provide nucleation sites. It is then aged to a stable size and composition, at a temperature in the region of $300{ }^{\circ} \mathrm{C}\left(\omega_{\text {iso }}\right)$. Finally, it is transformed to nanoscale $\alpha$ by ageing at temperatures around $500{ }^{\circ} \mathrm{C}$. If this transformation sequence can be understood, the industrial prize is the realisation of stronger $\beta$-Ti alloys than can be manufactured in thick sections. 
Table 1: Heat treatments and corresponding nomenclature for the heat treatments employed on Ti-5553. All samples were initially heat treated above the $\beta$-transus followed by water quenching (WQ). The subsequent lower temperature heat treatments were followed by aircooling (AC).

\begin{tabular}{l|lllll} 
Label & \multicolumn{5}{|c}{ Heat Treatment } \\
\hline $\mathrm{A}-0$ & $900^{\circ} \mathrm{C} / 0.5 \mathrm{~h}$ & $\mathrm{WQ}$ & & \\
$\mathrm{A}-1$ & $900^{\circ} \mathrm{C} / 0.5 \mathrm{~h}$ & $\mathrm{WQ}$ & $300^{\circ} \mathrm{C} / 1 \mathrm{~h}$ & $\mathrm{AC}$ & \\
$\mathrm{A}-2$ & $900^{\circ} \mathrm{C} / 0.5 \mathrm{~h}$ & $\mathrm{WQ}$ & $300^{\circ} \mathrm{C} / 2 \mathrm{~h}$ & $\mathrm{AC}$ & \\
$\mathrm{A}-4$ & $900^{\circ} \mathrm{C} / 0.5 \mathrm{~h}$ & $\mathrm{WQ}$ & $300^{\circ} \mathrm{C} / 4 \mathrm{~h}$ & $\mathrm{AC}$ & \\
$\mathrm{A}-8$ & $900^{\circ} \mathrm{C} / 0.5 \mathrm{~h}$ & $\mathrm{WQ}$ & $300^{\circ} \mathrm{C} / 8 \mathrm{~h}$ & $\mathrm{AC}$ & \\
$\mathrm{B}-2$ & $900^{\circ} \mathrm{C} / 0.5 \mathrm{~h}$ & $\mathrm{WQ}$ & $300^{\circ} \mathrm{C} / 8 \mathrm{~h}$ & $500^{\circ} \mathrm{C} / 2 \mathrm{~h}$ & $\mathrm{AC}$ \\
$\mathrm{C}-1$ & $900^{\circ} \mathrm{C} / 0.5 \mathrm{~h}$ & $\mathrm{WQ}$ & $400^{\circ} \mathrm{C} / 1 \mathrm{~h}$ & $\mathrm{AC}$ & \\
$\mathrm{C}-2$ & $900^{\circ} \mathrm{C} / 0.5 \mathrm{~h}$ & $\mathrm{WQ}$ & $400^{\circ} \mathrm{C} / 2 \mathrm{~h}$ & $\mathrm{AC}$ & 77 \\
$\mathrm{C}-4$ & $900^{\circ} \mathrm{C} / 0.5 \mathrm{~h}$ & $\mathrm{WQ}$ & $400^{\circ} \mathrm{C} / 4 \mathrm{~h}$ & $\mathrm{AC}$ & 78 \\
$\mathrm{C}-8$ & $900^{\circ} \mathrm{C} / 0.5 \mathrm{~h}$ & $\mathrm{WQ}$ & $400^{\circ} \mathrm{C} / 8 \mathrm{~h}$ & $\mathrm{AC}$ & 79 \\
& & & & & 77
\end{tabular}

It appears that fine-scale $\alpha$ nucleates either within the ${ }_{81}$ core of the $\omega$ precipitate, or in a depleted zone adjacent to the $\omega$ precipitate $[3,12]$. It is generally believed that ${ }^{82}$ $\omega$ precipitation is detrimental to material properties and ${ }^{83}$ should be avoided as it is embrittling, for example [13].

This work aims to distinguish the extent of strength- ${ }^{85}$ ening provided by $\alpha$ and $\omega$ phases in Ti-5553. In-situ ${ }^{86}$ small angle neutron scattering (SANS) was performed to ${ }^{87}$ study nanoscale particle evolution during a two step age- ${ }^{88}$ ing heat treatment of $300^{\circ} \mathrm{C}$ followed by a temperature hold at $500^{\circ} \mathrm{C}$. The SANS measurements are complemented by atom probe tomography (APT) to give compositional information, ex-situ transmission electron mi- ${ }^{91}$ croscopy (TEM) to confirm phase identification and size ${ }^{92}$ distribution locally, and X-ray diffraction (XRD) for addi- ${ }^{93}$ tional confirmation of phase identification. SANS is shown ${ }^{94}$ to be an excellent method for identifying $\omega$ precipitation. ${ }^{95}$ It is clarified that $\omega$ precipitation hardens Ti-5553, but not ${ }^{96}$ as significantly as the $\alpha$ phase. Finally, the microstructural ${ }^{97}$ parameters of the $\omega$ phase are fully quantified.

\section{Experimental Details}

The Ti-5553 forged billet used in this work has pre- ${ }^{102}$ viously been studied and reported $[4,8]$. All samples ${ }^{103}$ were prepared by initially heat treating Ti-5553 at $900{ }^{\circ} \mathrm{C}^{104}$ ( $\sim 50{ }^{\circ} \mathrm{C}$ above the $\beta$ transus [4]) for 30 min followed by water quenching. This initial condition is hereafter la- ${ }^{106}$ belled A-0. The ageing conditions performed for study by ${ }^{107}$ a combination of TEM, XRD, APT and Vickers microhardness testing are presented in Table 1, along with cor- ${ }^{109}$ responding nomenclature. All samples were air-cooled fol ${ }^{110}$ lowing the final heat treatments.

\subsection{X-ray Diffraction (XRD)}

The A- 8 heat treated sample and the sample follow- ${ }_{115}$ ing in-situ SANS (sample B-2) were both measured in $\mathrm{a}_{116}$ laboratory XRD. The instrument used was a PANalytical ${ }_{117}$ X'Pert Pro MPD fitted with an X'celerator detector, using ${ }_{118}$ $\mathrm{Cu}-\mathrm{K}_{\alpha} \mathrm{X}$-ray radiation with a characteristic wavelength of

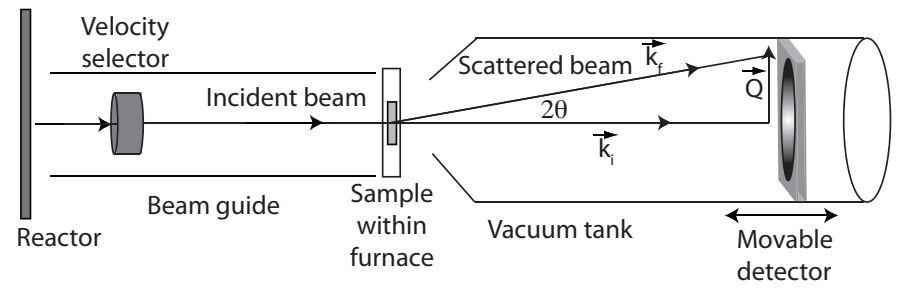

Figure 1: Schematic of the experimental arrangement used to perform pinhole small angle neutron scattering at HFIR, ORNL, Tennessee, USA.

\section{$1.541 \AA$ at $40 \mathrm{kV}$ and $40 \mathrm{~mA}$ current. Data were collected} for 1 hour over a range of $20-100^{\circ} 2 \theta$. Phase identification was performed by comparison to powder patterns using CrystalDiffract software.

\subsection{Transmission Electron Microscopy (TEM)}

Specimens for TEM analysis were removed by sparkerosion and thinned using twin-jet electropolishing in a solution of 8 vol. $\% \mathrm{H}_{2} \mathrm{SO}_{4}$ in methanol at $-40^{\circ} \mathrm{C}$ and $18 \mathrm{~V}$. TEM foils were examined using a JEOL JEM 2000FX microscope.

The ageing conditions studied in TEM were selected to aid the interpretation of the SANS experimentation. All microscopy was performed ex-situ at room temperature.

\subsection{Small Angle Neutron Scattering (SANS)}

SANS measures the shape and intensity of the coherent elastic scattering at small angles from the incident beam. The angles are much smaller than classical diffraction angles [14-21], typically under $5^{\circ}$. Pinhole SANS can provide scattering patterns from structures or fluctuations in composition or density on the length scale of about 1 to $100 \mathrm{~nm}$, corresponding to the size of smaller precipitates in engineering alloys.

SANS was performed at the Oak Ridge National Laboratory (ORNL) High Flux Isotope Reactor (HFIR) on the General Purpose Small Angle Neutron Scattering (GPSANS) instrument [22]. The set-up is illustrated in Figure 1. A mechanical velocity selector defined the incident neutron wavelength, in this case $\lambda=4.75 \AA$ with a $10 \%$ spread, and the beam was collimated prior to the sample by a pair of apertures. $\mathbf{k}_{\mathbf{i}}$ is the incident wave vector with magnitude $k=2 \pi / \lambda$. The scattering vector $\mathbf{Q}$ is the difference between incident and scattered wave vectors $\mathbf{Q}=\mathbf{k}_{\mathbf{f}}-\mathbf{k}_{\mathbf{i}}$. The magnitude of $Q$ quantifies the lengths of the reciprocal space $Q=\frac{4 \pi}{\lambda} \sin \theta$, where $2 \theta$ is the scattering angle.

A $10 \mathrm{~mm}$ square $1 \mathrm{~mm}$ thick sample of quenched Ti5553 (A-0) was placed in a beam-line specific, argon gas atmosphere furnace and positioned in the beam-line. The sample to detector distance was set at $4 \mathrm{~m}$, an aperture of $6 \mathrm{~mm}$ was used, and measurement count times were $900 \mathrm{~s}$. The detector array was offset from the centre in order to measure a larger $Q$ range. 
The SANS raw data was reduced to absolute scattering cross section $\partial \Sigma(Q) / \partial \Omega$ using standard software in the HFIR Wavemetrics Igor package [22]. Data were corrected for: transmissions $T(\lambda)$ measured with the central beam stop removed and the incident beam attenuated, for backgrounds from the empty furnace, for dark current background in the detector, and with the isotropic scattering from a $3 \mathrm{~cm}$ thick PMMA plate for detector pixel sensitivity variations. Data were placed on the absolute scale by the ratio of the area detector count rate to the beammonitor count rate in the empty-beam transmission measurement for each wavelength.

Room temperature data were collected first, after which the furnace temperature was raised to $300^{\circ} \mathrm{C}$ at $\sim 1^{\circ} \mathrm{C} / \mathrm{s}$ and held at this temperature for $8 \mathrm{~h}$ while in-situ measurements were recorded every 15 minutes. After the $8 \mathrm{~h}$ thermal exposure the temperature was raised to $500^{\circ} \mathrm{C}$ at $\sim 1^{\circ} \mathrm{C} / \mathrm{s}$ and held at this temperature for $2 \mathrm{~h}$ with the same measurement times.

\subsection{Atom Probe Tomography (APT)}

Atom probe tomography (APT) is a technique capable of concurrently determining 3D material structure and chemical composition at the atomic scale, and is equally sensitive to all elements. Numerous detailed textbooks of the physical principles, sample preparation and APT experimental techniques are now available, for example $[23,24]$.

Needle-shaped atom probe samples of A-8 condition ${ }^{172}$ were prepared using the lift-out method on an FEI He-173 lios NanoLab 600 DualBeam $^{\text {TM }}$ focused ion beam (FIB) ${ }^{174}$ system equipped with an Omniprobe ${ }^{\mathrm{TM}}$. A detailed de-175 scription of the FIB lift-out and tip sharpening procedure can be found elsewhere [25-27].

APT experiments were performed in laser mode using $_{177}$ a Cameca LEAPTM 4000X HR equipped with a $355 \mathrm{~nm}_{178}$ laser at Harvard University, USA, and LEAP ${ }^{\mathrm{TM}} 3000 \mathrm{X} \mathrm{HR}_{179}$ with a $512 \mathrm{~nm}$ laser at the University of Oxford, UK. The 180 tip temperatures were $40 \mathrm{~K}$ and pulse energies of $0.05 \mathrm{~nJ} \mathrm{~J}_{181}$ (LEAP 4000X HR) and 0.2nJ (LEAP 3000X HR) were ${ }_{182}$ used. After data collection, runs were reconstructed util- ${ }_{183}$ ising IVAS $^{\mathrm{TM}}$ data analysis software, using the estimated ${ }_{184}$ tip radius of the specimens from SEM imaging.

\section{Results}

\subsection{Hardness Testing}

Vickers micro-hardness test results for Ti-5553 in the ${ }^{190}$ quenched condition (A-0) and all heat treatments are pre- ${ }^{191}$ sented in Figure 2. $1 \mathrm{~h}$ of heat treatment at $300^{\circ} \mathrm{C}$ (sample ${ }^{192}$ A-1) resulted in an increase in hardness from $\sim 280$ to $310^{193}$ $\mathrm{Hv}$. The hardness increased further to $\sim 325 \mathrm{Hv}$ with $7^{194}$ more hours heat treatment at $300^{\circ} \mathrm{C}$ (sample A-8). When ${ }^{195}$ the temperature was ramped to $500^{\circ} \mathrm{C}$ and held for two $0^{196}$ hours (condition B-2) there was a significant increase in ${ }^{197}$ hardness to $\sim 515$ Hv. Separate experiments showed that ${ }^{198}$

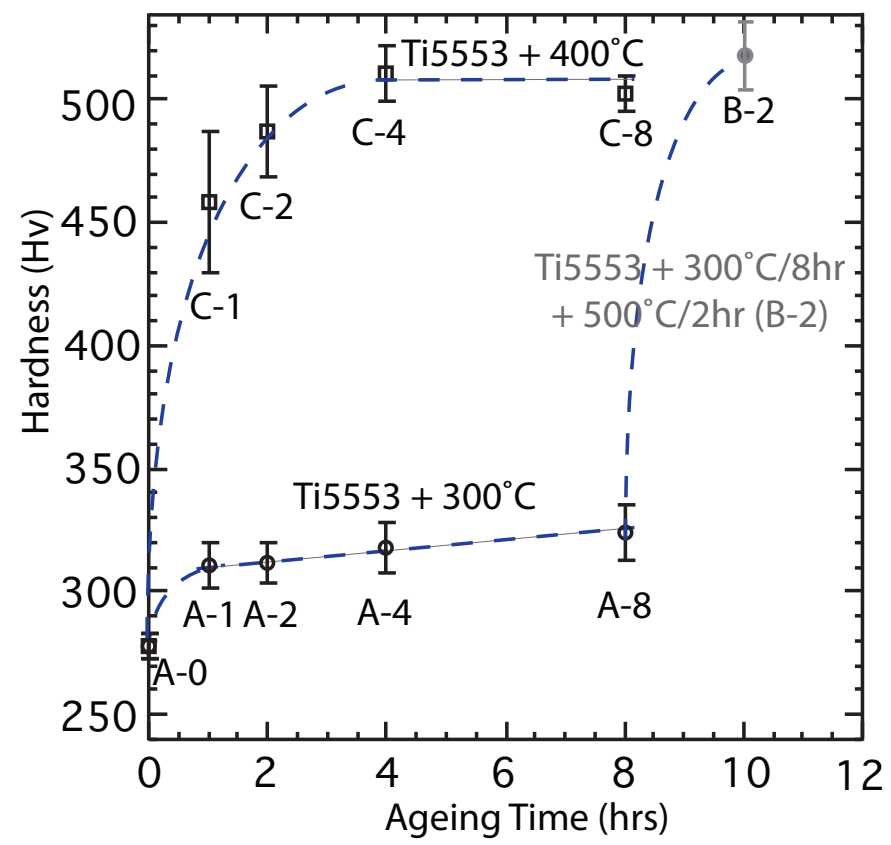

Figure 2: Evolution of Vickers micro-hardness of Ti-5553 as a function of ageing time. The data presented shows the hardness of the quenched material $(\mathrm{A}-0), 300^{\circ} \mathrm{C}$ and $400^{\circ} \mathrm{C}$ samples with ageing times between 1 and $8 \mathrm{~h}$, labelled $\mathrm{A}-1$ to $\mathrm{A}-8$ and $\mathrm{C}-1$ to C-8 respectively. The hardness of sample B-2 which received a $300{ }^{\circ} \mathrm{C} / 8 \mathrm{~h}+500{ }^{\circ} \mathrm{C} / 2 \mathrm{~h}$ ageing heat treatment is also presented. Trendlines have been inserted to the data as a guide to the eye.

ageing at $400{ }^{\circ} \mathrm{C}$ for $1 \mathrm{~h}$ (sample $\mathrm{C}-1$ ) resulted in a large hardness increase from $\sim 280$ to $460 \mathrm{Hv}$, and a further 7 hours thermal exposure increased the hardness to $\sim 500$ Hv (sample C-8).

\subsection{X-ray Diffraction}

The XRD profiles for sample A- 8 and B- 2 are presented in Figures $3 \mathrm{a}$ and $\mathrm{b}$ respectively. The lattice constants of $\alpha$ and $\beta$ for Ti-5553 were previously determined [8] and corresponding peak positions are presented in Figure 3. The peak positions based on $\omega$ in pure Ti [28] and $\alpha^{\prime \prime}$ in the $\beta$-Ti alloy Ti-2448 [29] are also shown.

The doublets observed in the $\beta$ matrix peaks in Figure $3 a$ are due to diffraction arising from both $K_{\alpha 1}$ and $\mathrm{K}_{\alpha 2}$ emissions. The diffraction patterns of the two heat treatments are markedly different, with sample B-2 exhibiting much broader peaks than A-8. There are numerous microstructural effects that can result in broad diffraction peaks, for example dislocations, twinning and coherency strains. In this case it is presumably related to the nanometer scale of the alpha particles by the Scherrer equation.

A number of low intensity peaks have not been labelled as one cannot definitively determine the corresponding diffracting crystal structure. A clear peak at $44.4^{\circ}$ in Figure $3 \mathrm{a}$ is evidence of extensive $\omega$ precipitation (labelled $\omega(020))$ in sample A-8. This peak is not present in B-2 (Figure $3 \mathrm{~b}$ ). The peak at $35.5^{\circ}$ of the same figure may 


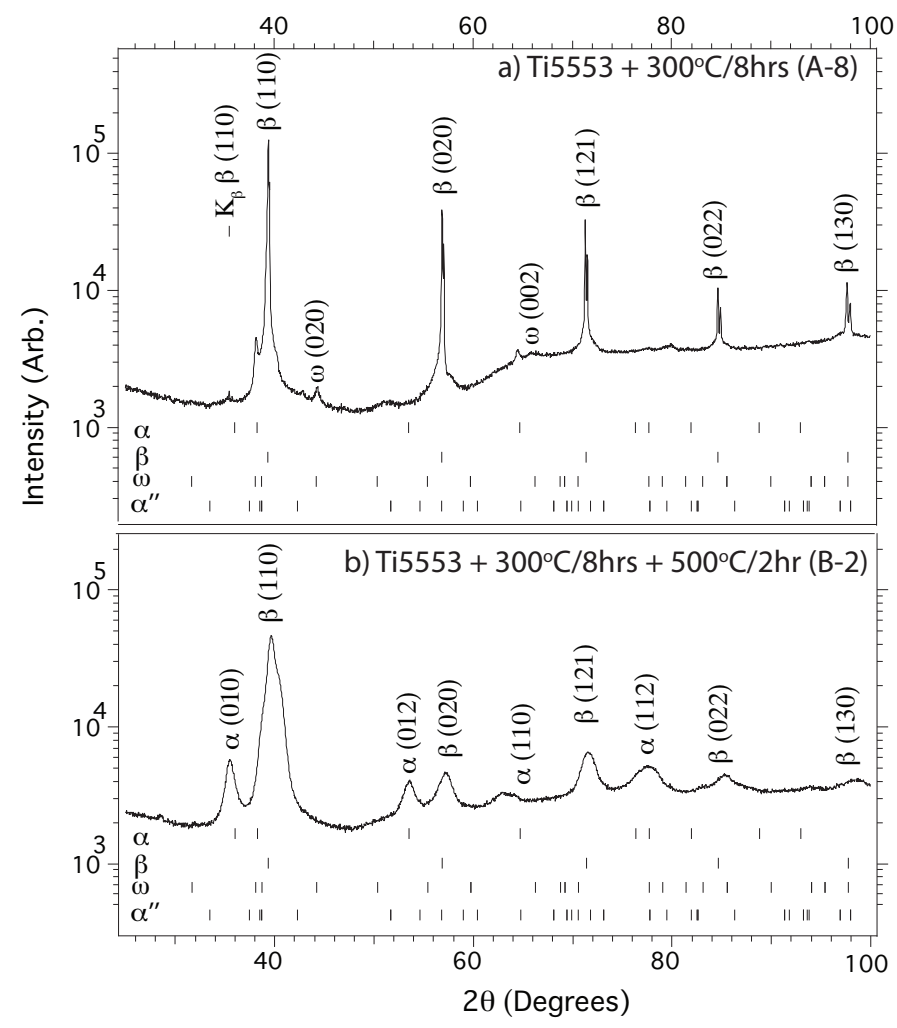

Figure 3: X-ray diffraction patterns for a) $300^{\circ} \mathrm{C} / 8 \mathrm{~h}$ and b) $300^{\circ} \mathrm{C} / 8 \mathrm{~h}+500^{\circ} \mathrm{C} / 2 \mathrm{~h}$ heat treated samples.

arise from the $\mathrm{Cu} \mathrm{K} \mathrm{K}_{\beta}$ (011) $\beta$ position which has not been completely removed with the secondary monochromator.

Strong peaks at $35.4^{\circ}, 53.2^{\circ}$ and $77.7^{\circ}$ are evidence of extensive $\alpha$ precipitation in sample B-2, Figure $3 \mathrm{~b}$.

\subsection{Transmission Electron Microscopy (TEM)}

Figure 4 shows the evolution of the TEM diffraction patterns during thermal exposure along with corresponding dark field images and two schematic diagrams to aid analysis. All the diffraction patterns are viewed parallel to the [113] zone axis for all the samples. B-2 is the sample following the SANS experiment. It is reasonable to assume that the microstructure at room temperature is representative of the microstructure at $300^{\circ} \mathrm{C}$, as it is well below the $\beta$ transus temperature of $\sim 845^{\circ} \mathrm{C}$ for Ti-5553 [4].

The streaking along the $\langle 112\rangle_{\beta}$ in the initial condition TEM diffraction pattern (Figure $4 \mathrm{a}$ ) is associated with $\omega_{\text {ath }}[3,12]$. The very faint spots at $1 / 2<112>_{\beta}$ are reflections from $\alpha^{\prime \prime}$ phase. These were most obvious in sample A-0. Distinct spots were seen to form in the diffraction patterns and grow in intensity at $1 / 3$ and $2 / 3<112>_{\beta}$ with increasing thermal exposure times up to $8 \mathrm{~h}$. These spots correspond to the $\omega_{\text {iso }}$ phase. There were no obvious reflections due to the $\alpha$ phase in any of the diffraction patterns of the $300^{\circ} \mathrm{C}$ heat-treated samples. The TEM diffraction pattern of sample B-2 (Figure 4j) was markedly different to samples A-1 to A-8. There were clear strong $\alpha$ reflections which can be identified using the schematic

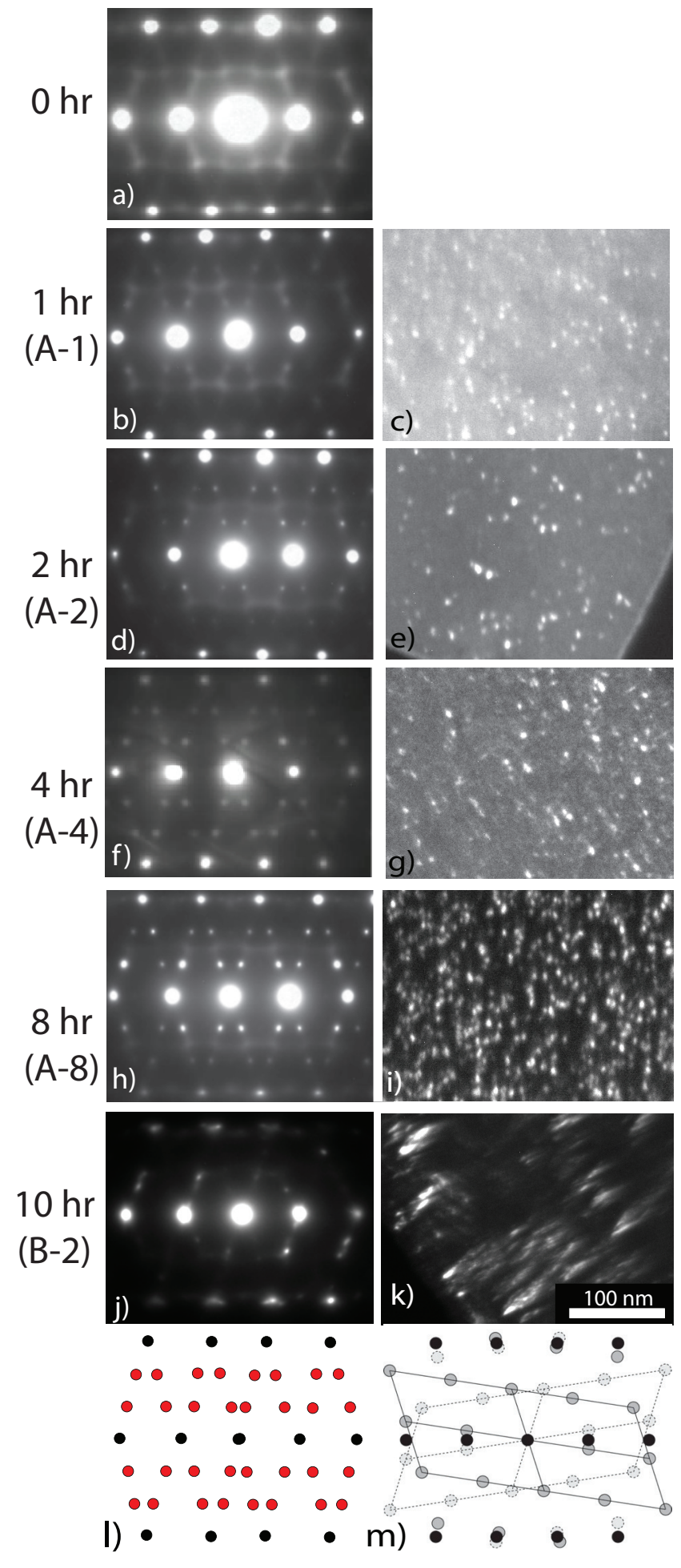

Figure 4: a-k) TEM diffraction pattern evolution and associated dark field imaging for samples with ageing times of $0 \mathrm{~h}-8 \mathrm{~h}$ at $300^{\circ} \mathrm{C}$ (samples A-0 to A-8) and $300^{\circ} \mathrm{C} / 8 \mathrm{~h}+500^{\circ} \mathrm{C} / 2 \mathrm{~h}$, (sample B-2). All diffraction patterns are viewed parallel to the [113] zone axis. Dark field images are taken from the $1 / 3<112>$ reflection associated with the $\omega$ phase. 1) Schematic illustrating the position of diffraction spots due to the $\omega$ phase (black: $\beta$ spots; red: $\omega$ spots) and $\mathrm{m}$ ) the $\alpha$ phase (black: $\beta$ spots; light and dark grey: $\alpha$ spots). 


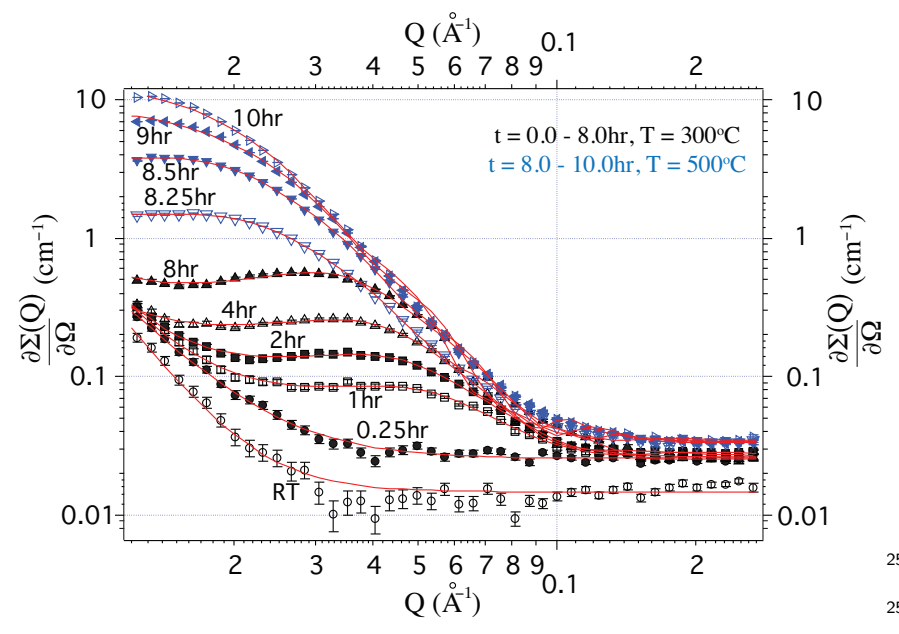

Figure 5: The evolution of Ti-5553 SANS scattering curves with tin measured at room temperature (RT) and in-situ at $300^{\circ} \mathrm{C}$ for $0-8 \mathrm{~h}$, after which the temperature was ramped to $500^{\circ} \mathrm{C}$, plotted on a log$\log$ scale. The times represents the time at which the measurement263 was finished, with each measurement taking $0.25 \mathrm{~h}$. Solid lines rep-264 resent model fits based on monodisperse disc-shaped particles. $(\mathrm{m})$, and the reflections associated with $\omega$ were fully ${ }^{267}$ almost fully removed compared to (h).

It was not possible to obtain dark field images from ${ }^{268}$ the reflections at at $1 / 3$ and $2 / 3<112>_{\beta}$ in the initial ${ }^{269}$ condition, however the micrographs produced from an $\omega^{270}$ reflection for the samples A-1 to A-8 and B-2 are shown,271 Figure 4. It is apparent that $\omega$ particles were of elliptical272 morphology when viewed in $2 \mathrm{D}$ with diameter $\sim 5-10 \mathrm{~nm},{ }^{273}$ The volume fraction appeared to increase with thermal ex-274 posure at $300^{\circ} \mathrm{C}$ up to $8 \mathrm{~h}$, however foil thickness can in-275 fluence the observed volume fraction. The dark field image ${ }^{276}$ of sample B-2 (Figure 4k) showed much larger particles. ${ }^{277}$

\subsection{Small Angle Neutron Scattering}

The sample scattered neutrons quite isotropically $\mathrm{at}^{280}$ room temperature and all elevated temperature measure- ${ }^{281}$ ments. This was deduced from analysis of the neutron ${ }^{282}$ counts in the $2 \mathrm{D}$ detector. The data for each measure- ${ }^{283}$ ment was azimuthally averaged, and the evolution of the $e^{284}$ fully reduced scattering curves with thermal exposure time ${ }^{285}$ are presented in Figure 5, plotted as absolute scattering ${ }^{286}$ cross-section $\partial \Sigma(Q) / \partial \Omega$ (commonly referred to as inten- ${ }^{287}$ sity) against the magnitude of the scattering vector $Q .{ }^{288}$

The room temperature measurement and first elevated ${ }^{289}$ temperature measurement showed no obvious scattering ${ }^{290}$ from nanoscale particles within the measured range of $Q{ }^{291}$ Figure 5. From TEM it was known that $\omega_{\text {ath }}$ is initially ${ }^{292}$ present (Figure 4a). Therefore scattering arising due to ${ }^{293}$ $\omega_{\text {ath }}$ may be apparent at a $Q$ range outside that measured ${ }^{294}$ in this work, or there may be no scattering arising from ${ }^{295}$ this phase if the $\omega_{\text {ath }}$ phase composition was the same $a^{296}$ the matrix. After $1 \mathrm{~h}$ of thermal exposure a broad peak ${ }^{297}$ was seen forming at $\sim 0.043 \AA^{-1}$, which grew in intensity ${ }^{298}$
Table 2: Nominal composition and the compositions of Ti-5553 measured by inductively coupled plasma optical emission spectrometry (ICP-OES) and by atom probe tomography (APT) for the bulk material. The APT samples have received a $+300^{\circ} \mathrm{C} / 8 \mathrm{~h}$ heat treatment. The subscripts 1 and 2 refer to needle 1 and needle 2 , which were measured on LEAP 4000X HR and LEAP 3000X HR instruments respectively. All compositions are in atomic $\%$.

\begin{tabular}{l|cccccc} 
Bulk Composition, at.\% & $\mathrm{Ti}$ & $\mathrm{V}$ & $\mathrm{Fe}$ & $\mathrm{Al}$ & $\mathrm{Mo}$ & $\mathrm{Cr}$ \\
\hline Nominal Composition & 81.1 & 4.7 & 0.3 & 8.8 & 2.5 & 2.7 \\
ICP-OES [4] & 80.8 & 4.9 & 0.3 & 8.7 & 2.6 & 2.7 \\
$\mathrm{APT}_{1}$ & 80.6 & 5.1 & 0.2 & 8.5 & 1.7 & 3.2 \\
$\mathrm{APT}_{2}$ & 81.1 & 5.2 & 0.3 & 8.4 & 1.8 & 2.8
\end{tabular}

and shifts to lower $Q$ with increasing ageing time, with a peak position of $\sim 0.028 \AA^{-1}$ after $8 \mathrm{~h}$.

After $8 \mathrm{~h}$ at $300^{\circ} \mathrm{C}$ the temperature was ramped to $500^{\circ} \mathrm{C}$ and the scattering curve shape and intensity changed dramatically. After $8.25 \mathrm{~h}$ the intensity was lower than after $8 \mathrm{~h}$ in the $Q$ range of $0.037-0.043 \AA^{-1}$. The intensity at low $Q$ increased with thermal exposure time at $500^{\circ} \mathrm{C}$ and appeared to plateau at the lowest values of $Q$. Modelling is required in order to deduce information of particle size, shape and volume fraction from SANS measurements.

\subsection{Atom Probe Tomography}

Two APT measurements are presented in this work, referred to as needle 1 and needle 2 respectively. Both needles were prepared from the A- 8 heat treated condition.

The two needles were analysed in separate LEAP systems equipped with different laser pulse wavelengths, in order to ensure any segregation behaviour was not a result of laser-artefacts. Datasets containing 56 million and 51 million ions for needles 1 and 2 were obtained respectively. The bulk compositions determined by APT are in excellent agreement with those previously determined by inductively coupled plasma optical emission spectrometry (ICP-OES) [4], Table 2. APT reconstructions are presented in Figure 6, showing 3nm thick slices through the entire datasets. Along with good agreement between needles 1 and 2 in terms of compositions, Figure 6 reveals the microstructures are very similar, with dense dispersions of small $(<10 \mathrm{~nm}$ diameter) precipitates throughout. The precipitates are highlighted by Ti 86.5 at.\% isosurfaces, thus in comparison to the bulk they are enriched in Ti. The similarity in compositions between matrix and precipitates for the main element, $\mathrm{Ti}$, prevented the use of clustering algorithms to isolate the latter, but the isosurfaces employed in both needles 1 and 2 enable generation of proxigrams to examine in detail changes in chemistry.

Proxigrams of A-8 are presented in Figure 7, averaging across (i) 687 precipitates and (ii) 819 precipitates. The chemical interface width was approximately $4 \mathrm{~nm}$. The solute additions were rejected from the precipitates, resulting in Ti enriched particles. The average Ti concentration within the isosurface of the particles was approximately 10 at.\% more than the matrix. The cores of the precipitates are the regions of highest Ti enrichment. These cores are 


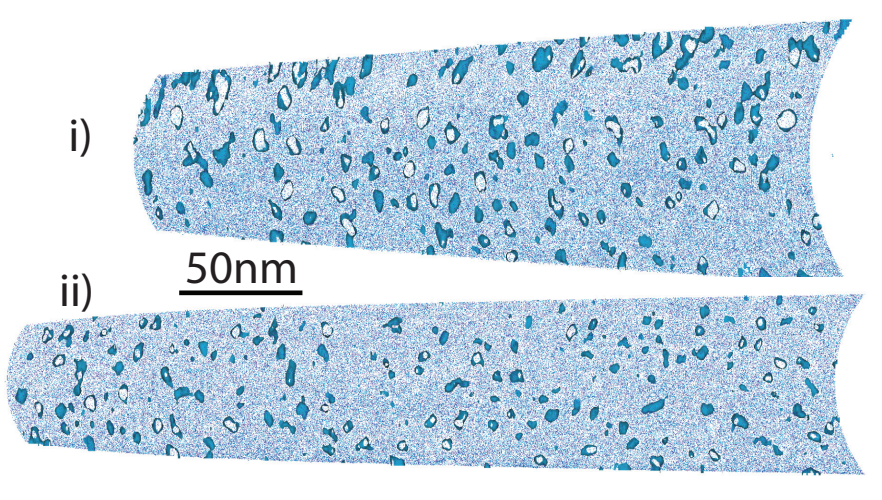

Figure 6: APT reconstructions of a Ti 86.5 at.\% isosurface on a $3 \mathrm{~nm}$ thick slice through the whole map for Ti-5553+300 ${ }^{\circ} \mathrm{C} / 8 \mathrm{~h}$ needles. i) Needle 1 was measured on a LEAP 4000X HR and ii) needle 2 was measured on a LEAP 3000X HR. Al (blue) and V (purple) are shown only, for clarity.
14 at.\% higher in Ti concentration than the matrix. The Ti composition of the matrix was depleted by $\sim 1$ at. $\%$ compared to the bulk composition. The concentration of all solute additions combined was approximately four times higher in the matrix than in the precipitates.

\section{Discussion}

\subsection{Atom Probe Tomography}

APT has previously been applied to the study of precipitation in Ti-5553 by Nag et al. [3, 11]. They could not discern precipitation in Ti- 5553 aged at $400{ }^{\circ} \mathrm{C} / 2 \mathrm{~h}$ by APT, and attributed this to the low diffusivities of the elements at this temperature [11]. Nag et al. also published APT results identifying $\omega$ and $\alpha$ precipitates in $\mathrm{Ti}^{-339}$ 5553 aged at the lower temperature of $350{ }^{\circ} \mathrm{C} / 2 \mathrm{~h} \mathrm{[3]}$. The $\mathrm{T}_{340}$ phases were distinguished based on solute addition com $^{340}$ positional profiles that fluctuate within \pm 1 at.\% [3].

The two proxigrams presented in this work are from $_{343}^{342}$ 687 and 819 identified particles, and show a very clear $\operatorname{and}^{344}$ significant decrease in all solute additions within the pre- ${ }_{345}$ cipitates. Based upon the corresponding TEM (Figure $4 \mathrm{~h}^{345}$ \& i) for Ti- 5553 aged at $300^{\circ} \mathrm{C} / 8^{\circ} \mathrm{C}$ it is reasonable to identify these precipitates as the $\omega$ phase. It is of particular significance that the $\omega$ phase is depleted in Al. It is debated in the literature whether $\alpha$ precipitates nucleate ${ }^{348}$ from within the $\omega$ precipitates, at the $\omega / \beta$ interface, or $^{349}$ whether the $\omega$ precipitates undergo a solid state transfor ${ }^{350}$ mation to form the $\alpha$ precipitates $[12,30-36]$. Given that ${ }^{351}$ $\mathrm{Al}$ is the primary $\alpha$ stabiliser in this alloy, it seems un- ${ }^{352}$ likely that it would nucleate in an $\omega$ core so depleted in $^{353}$ this element. It is more logical that $\alpha$ would precipitate ${ }^{354}$ at the $\omega / \beta$ interface where there is slight $\mathrm{Al}$ enrichment, ${ }^{355}$ which is the precipitation mechanism proposed by Nag $e t^{356}$ al. [3]. APT studies of longer ageing times are required in $^{357}$ order to be definitive.

Using a straightforward atom count analysis of needle ${ }^{359}$ 1 gives an $\omega$ volume fraction of approximately $7 \%$ in the

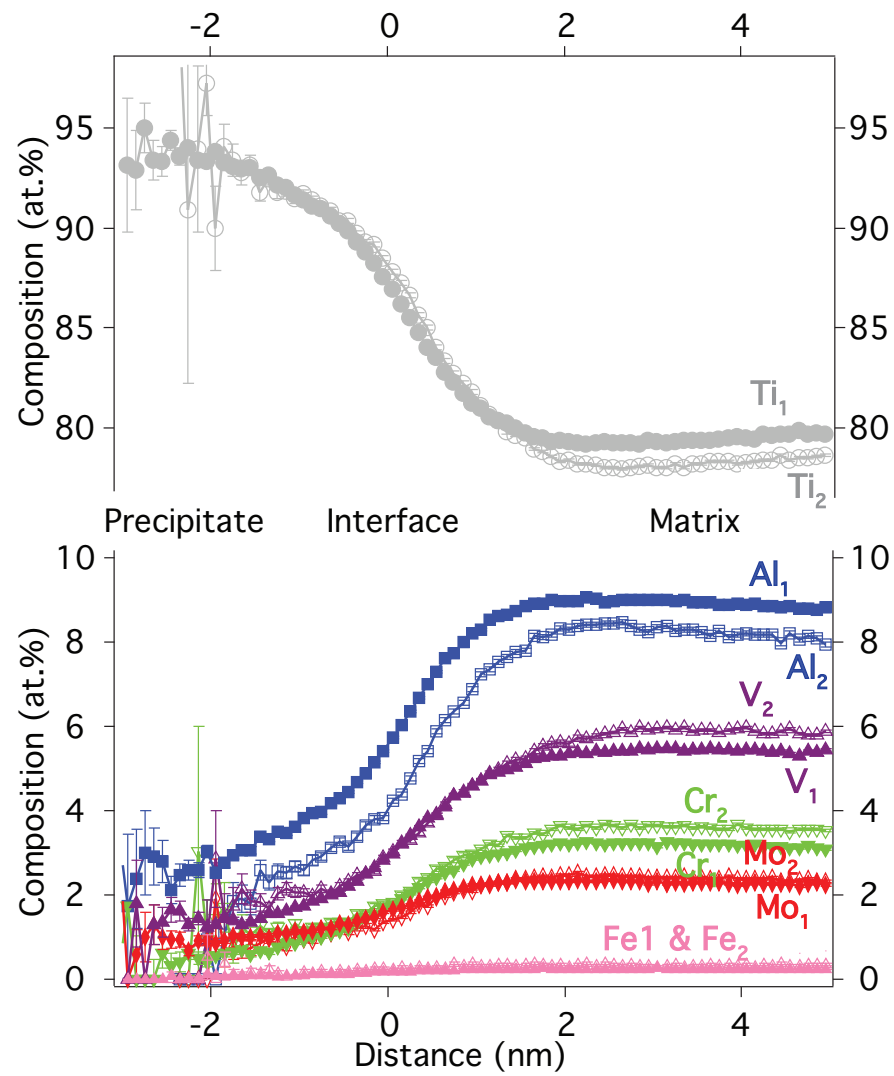

Figure 7: Proxigrams of Ti-5553 $+300{ }^{\circ} \mathrm{C} / 8 \mathrm{~h}(\mathrm{~A}-8)$ heat treatment averaged through identified precipitates in LEAP 4000X HR (subscript 1) and in LEAP 3000X HR (subscript 2).

APT data (needle 2 yields a fraction of $4 \%$, which while comparable is from the lower mass-resolution on the $3000 \mathrm{X}$ HR). Considering the error in atomic fractions if the lever rule is applied $n_{i, \text { error }}=\left(n_{i, \text { ppt }} \phi+n_{i, \text { matrix }}(1-\phi)\right)-n_{i, \text { bulk }}$, where $n_{i}$ is the atomic fraction of element $i$ in the precipitate, matrix, or bulk, and $\phi$ is the precipitate volume fraction, the error is small. The maximum error in atomic fraction is less than 0.1 at. \% for $\mathrm{Ti}, \mathrm{Al}$ and $\mathrm{V}, 0.2$ at.\% for $\mathrm{Cr}$, and 0.5 at.\% for Mo, when the volume fraction of $7 \%$ is introduced to the equation.

\subsection{Transmission Electron Microscopy}

The TEM study shows the progressive development of $\omega$ spots when heat-treated at $300^{\circ} \mathrm{C}$. Imaging in dark field indicates an increase in volume fraction of the nanoscale precipitates, Figure 4, however this can be influenced by foil thickness. Nag et al. previously performed TEM on a Ti- $-5553+350{ }^{\circ} \mathrm{C} / 2 \mathrm{~h}$ heat-treated sample, and the difference in the extent of precipitation between their $350{ }^{\circ} \mathrm{C}$ heat treatment, and the $300^{\circ} \mathrm{C}$ heat treatment performed in this work is dramatic [3]. Their sample exhibited very strong $\alpha$ and $\omega$ reflections after $2 \mathrm{~h}$ heat treatment. In this work there are no $\alpha$ reflections after $300{ }^{\circ} \mathrm{C} / 2 \mathrm{~h}$ heat treatment $(4 \mathrm{~d})$, and the $\omega$ reflections are very weak in comparison to those presented by Nag et al. [3]. 
Sample B-2, which has had the additional exposure of $500{ }^{\circ} \mathrm{C} / 2 \mathrm{~h}$, shows a significant decrease in intensity from the $\omega$ reflections, to the point that they may have been totally removed. The $\alpha$ reflections are now clearly present after this heat treatment, Figure $4 \mathrm{j}$. This indicates that $\omega$ has gone into dissolution if one does not recognise the $\omega$ to $\alpha$ transformation, however this transformation is the alternative interpretation [8].

\subsection{X-ray Diffraction}

It is clear that $\omega$ is present after $300^{\circ} \mathrm{C} / 8 \mathrm{~h}$ heat treatment, Figure 3 . The XRD pattern is dramatically different following the $500^{\circ} \mathrm{C} / 2 \mathrm{~h}$ thermal exposure, with no apparent $\omega$ reflections and strong $\alpha$ peaks present. This agrees well with the TEM observations. Due to the low intensity of $\omega$ reflections they can be difficult to distinguish from background in laboratory XRD, so care should be taken with its application. It is for this reason that TEM diffraction is the primary analysis tool for $\beta$-Ti alloy precipitation ${ }_{414}$ studies.

\subsection{Small Angle Neutron Scattering}

The SANS data show a scattering peak forming during ${ }^{417}$ thermal exposure due to precipitation, Figure 5 . However in order to deduce microstructural parameters such as par- ${ }^{41}$ ticle size, shape and volume fraction, modelling is required. ${ }^{420}$ The model applied should be based on complementary mi- ${ }^{421}$ croscopic analysis, such as the TEM study in this work. ${ }^{42}$ In-situ SANS was recently applied to the study of pre- ${ }^{423}$ cipitation at $400{ }^{\circ} \mathrm{C}$ in the $\beta$-Ti alloy, Gum metal, with ${ }^{424}$ different processing conditions [37]. The scattering curves ${ }^{425}$ in this work show similar shape to the cold-rolled Gum ${ }^{426}$ metal, however the analysis of cold-rolled Gum metal was ${ }^{427}$ confounded by co-precipitation of the $\alpha$ phase. As the $\omega^{428}$ particles appear to be circular in the TEM imaging as was ${ }^{429}$ the case for Gum metal, the SANS model for disc-shaped ${ }^{430}$ particles previously developed is applied to the Ti-5553 SANS data of this work [37].

The SANS model employed in this work is described ${ }^{43}$ elsewhere in extensive detail [37], and is summarised here. ${ }^{434}$ The model was developed in the FISH software package ${ }^{435}$ [38] and fits to the data by a least squares refinement. ${ }^{43}$ Although the model fits well to the data, Figure 5, it may ${ }^{437}$ not be a unique solution. Disc-shaped particles for $\omega$ are reasonable based upon the TEM and APT. A model using ${ }^{439}$ elliptical particles rather than discs also fitted to the data, and the fitting parameters of both models were in $\operatorname{good}^{441}$ agreement with the exception of the disc radius and larger ${ }^{442}$ elliptical radius. The model elliptical radius was slightly ${ }^{443}$ smaller than the model disc radius. The residual error ${ }^{444}$ between data and model fit was larger for the ellipse model. ${ }^{445}$

The disc model defines the probability of small angle ${ }^{446}$ scattering (SAS) from non-dilute uniform monodisperse ${ }^{447}$ discs as

$\partial \Sigma(Q) / \partial \Omega=N V^{2}(\Delta \rho)^{2} P(Q)_{\operatorname{Discs}} S(Q)_{\mathrm{HS}}+a Q^{-n}+\mathrm{BKG}_{451}$ where $P(Q)_{\text {Discs }}$ is the form factor or shape function of the disc shaped particles. $P(Q)$ depends on the size and shape of the particle and is normalised such that $P(Q=0)=1.0$ [39]. The form factor has an associated impenetrable hard sphere structure factor $S(Q)_{\mathrm{HS}}$ [40]. The structure factor is required at higher volume fractions to account for the interference from waves scattered by adjacent particles. BKG is a small flat background to account for incoherent scattering, and $a Q^{-n}$ accounts for scattering from the precipitate/matrix interface. $N$ is the number of particles per unit volume, $V$ is the volume of one particle. Note that the dispersed particle volume fraction $\phi=N V . \Delta \rho=\rho_{\text {ppt }}-\rho_{\text {matrix }}$ is the neutron scattering length density difference between the particle and its matrix. The scattering length density of phase $x$ is

$$
\rho_{x}=\left(\rho_{\text {mass }} N_{A} / M_{r}\right) \Sigma n_{i} b_{i}
$$

where $\rho_{\text {mass }}$ is the phase mass density, $N_{A}$ is Avogadro's number, $M_{r}$ is the relative molecular weight of the phase, $n_{i}$ is the atomic fraction of element $i$ in the phase, and $b_{i}$ is that element's associated neutron scattering length. Element partitioning between phases (which can be quantified by APT) will typically cause a neutron scattering length density difference. Therefore precipitates of different composition to the matrix can be identified by small angle scattering.

$P(Q)_{\text {Discs }}$ has three fitting parameters: scale (a fitting parameter particular to FISH equal to $\left.\phi(\Delta \rho)^{2}\right)$, disc diameter $D$, and disc length $L$. If the scattering contrast $(\Delta \rho)^{2}$ is known, the volume fraction $\phi$ can be determined from the $\phi(\Delta \rho)^{2}$ term. $S(Q)_{\mathrm{HS}}$ has two fitting parameters, the hard sphere diameter $D_{\mathrm{HS}}$ and the hard sphere volume fraction $V_{H S}$. Though this may be an effective approximation for non-spherical particles, the hard sphere volume fraction should be similar to $\phi$ in a good fit. The final fitting parameters are $a$ and $n$. For fits to the $300^{\circ} \mathrm{C}$ data, $n$ fitted to $\sim 4$ for early time measurements where a large linear region was present in the data at low $Q$, and so $n$ was then constrained at this value. This is standard Porod scattering and is presumably associated with scattering from the grains rather than nanoparticles. For fits to the $500^{\circ} \mathrm{C}$ data there was no linear region to fit so $a$ was put to zero. Thus, the model is composed of 10 fitting parameters in total. Initial estimates of these parameters are introduced into the model, and the model fit converges to the least squares minimum with the data by the Marquadt method.

The model results for $\omega$ particle diameter, length and $\phi(\Delta \rho)^{2}$ are presented in Figure 8 . The errors from the fitting routine are not included, but are of the order of $0.1 \mathrm{~nm}$ for particle length and radius, and $0.01 \times 10^{-10} \mathrm{~cm}^{-1}$ for $\phi(\Delta \rho)^{2}$. During the $300^{\circ} \mathrm{C} / 8 \mathrm{~h}$ heat treatment the $\omega$ particle mean diameter increases from $7.5-9.5 \mathrm{~nm}$, in good agreement with TEM, and the length increases from $4-5 \mathrm{~nm}$. Following the temperature ramp to $500{ }^{\circ} \mathrm{C}$ the applicability of a unimodal disc-shaped model may be questionable, as it is known that the $\alpha$ phase grows as nanoscale 
laths on ageing of quenched Ti-5553 at $570{ }^{\circ} \mathrm{C}[8]$. The two491 phase disc model fits the data well, and the results are pre-492 sented. Interestingly, the results still show agreement with 493 TEM, the discs grow in diameter to $\sim 20 \mathrm{~nm}$ and length 494 to $\sim 8 \mathrm{~nm}$. These dimensions are similar to the width of the $\alpha$ laths in the work of Jones et al. [8]. A rod model 495 is a logical approach to fit for an acicular $\alpha$ lath struc- ${ }_{496}$ ture. Therefore the disc model was reapplied and fitted $t_{0} \mathrm{C}_{497}$ the data, but with $L>D$. The fits were very poor, giving ${ }_{498}$ argument that the scattering is arising from nanoscale $\alpha_{499}$ particles that are still of disc shape $(D>L)$.

Subtracting the hard sphere diameter from either the particle diameter or length should give an approximation ${ }_{502}$ to an interparticle distance of the system. Following the $300^{\circ} \mathrm{C} / 8 \mathrm{~h} D_{\mathrm{HS}} \sim 16 \mathrm{~nm}$, giving an interparticle distance ${ }_{504}$ $\lambda_{d} \sim 7.5 \mathrm{~nm}$ which seems reasonable based on TEM (Fig- ${ }_{505}$ ure $4 \mathrm{i})$.

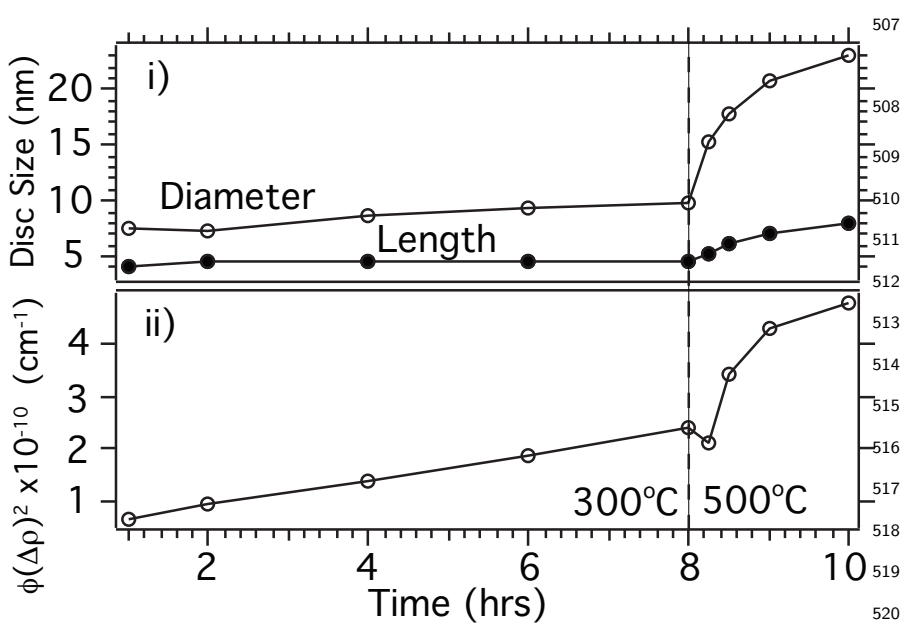

Figure 8: Model parameter results from fits to the measured $\mathrm{SANS}_{522}$ data for i) particle size, and ii) $\phi(\Delta \rho)^{2}$ term.

The neutron scattering length densities of $\beta$ and $\omega$ fol- $^{524}$ lowing the $300{ }^{\circ} \mathrm{C} / 8 \mathrm{~h}$ heat treatment are $\rho_{\beta}=-1.3 \times{ }^{525}$ $10^{10} \mathrm{~cm}^{-2}$ and $\rho_{\omega}=-1.7 \times 10^{10} \mathrm{~cm}^{-2}$ respectively, giving ${ }_{527}^{526}$ a scattering length density contrast of $\rho_{\omega}-\rho_{\beta}=-0.4 \times$ $10^{10} \mathrm{~cm}^{-2}$. These values are calculated from Eqn. (2), by: (i) calculating each phase mass density $\rho_{\text {mass }}$ and molec-528 ular weight $M_{r}$ from first principles based on the atomic weights and densities of each element in each phase $a d^{529}$ the atomic fraction in each phase determined in this work ${ }^{530}$ by APT; and (ii) using previously published scattering ${ }^{531}$ lengths of each element [41]. The compositions used for ${ }^{532}$ each phase were determined from the proxigram (needle 1,533 Figure 7), away from the interfacial region. As the scatter-534 ing length density difference $\Delta \rho=\rho_{\omega}-\rho_{\beta}$ is now known, the volume fraction can be deduced from the value of the $\mathrm{e}^{535}$ SANS model fitting parameter $\phi(\Delta \rho)^{2}$ (Figure 8). The 536 volume fraction from SANS after $300^{\circ} \mathrm{C} / 8 \mathrm{~h}$ is approx-537 imately $10 \%$, in reasonable agreement to the $7 \%$ deter-538 mined by APT. There is further agreement with the $\mathrm{SANS}_{539}$ model hard sphere volume fraction term $V_{H S}=12 \%$ for 540 the same heat treatment. As a crude first approximation, 541 if one assumes that the composition is constant during the $300{ }^{\circ} \mathrm{C}$ heat treatment, then the volume fractions are $\sim 3 \%, 4 \%$, and $6 \%$ after $1 \mathrm{~h}, 2 \mathrm{~h}$, and $4 \mathrm{~h}$ heat treatments respectively.

\subsection{Hardness Testing}

From the detailed microstructure analysis performed, it is not difficult to attribute the material properties to the precipitation process. The precipitation of $\omega$ phase at $300{ }^{\circ} \mathrm{C}(\mathrm{A}-8)$ corresponds to an increase in hardness of about $40 \mathrm{Hv}$ over the $8 \mathrm{~h}$ heat treatment. This represents a $\sim 15 \%$ increase in hardness compared to the quenched material. The subsequent age at $500^{\circ} \mathrm{C}(\mathrm{B}-2)$ increased the hardness by a further $\sim 200 \mathrm{Hv}$, which is an increase of $\sim 90 \%$ from the quenched material. This corresponds to the precipitation of $\alpha$ phase. The ageing at $400{ }^{\circ} \mathrm{C}$ shows similar hardness to the two-step ageing heat treatment, and so is presumably precipitating nanoscale $\alpha$ phase.

\subsection{Summary of Techniques}

TEM has been the primary analysis tool for the study of $\omega$, and by comparison of techniques it is clear why. It allows both crystallographic determination and two dimensional imaging. Laboratory XRD gives some initial insight to precipitation, however the $\omega$ peaks tend to get lost in the background. In Figure 3a, there is an indication that $\omega$ is present based on a single low intensity peak labelled as $\omega(020)$. This is not enough to be conclusive. Small angle scattering (SAS) detects early nucleation of $\omega$ most readily of all the techniques. The modelling of SAS data is not trivial, and requires complementary microscopy. APT is unrivalled in terms of quantifiable capabilities, but this work illustrates that measuring the earliest stages of precipitation is far from simple. The authors did not manage to quantify the precipitation that occurred following $300^{\circ} \mathrm{C} / 2 \mathrm{~h}$ ageing heat treatment, which has been identified by SANS and TEM. This may be a limitation of the detection efficiency, which is $\sim 37 \%$ on both current generation instruments used.

\section{Conclusions}

\subsection{Transmission Electron Microscopy and X-ray Diffrac- tion}

The volume fraction of $\omega$ phase in Ti-5553 appears to increase with thermal exposure time, when held at $300^{\circ} \mathrm{C}$ for $8 \mathrm{~h}$. A subsequent age of $500^{\circ} \mathrm{C} / 2 \mathrm{~h}$ precipitates $\alpha$ phase. The $\omega$ phase is removed.

\subsection{Atom Probe Tomography}

APT of the $300^{\circ} \mathrm{C} / 8 \mathrm{~h}$ material shows that the $\omega$ precipitates possess an atomic composition of approximately 94 at.\% Ti, 14 at.\% higher than the bulk composition, towards the core of the precipitate. The average Ti composition within the isosurface is approximately 10 at.\% higher than the bulk composition. The precipitates are 
depleted in all solute additions including Al. This is sig-597 nificant as $\mathrm{Al}$ is an $\alpha$ stabiliser, thus it is unlikely that $\alpha^{598}$ will subsequently nucleate from an $\omega$ core. It seems more ${ }_{600}^{599}$ reasonable that it will nucleate at the $\omega / \beta$ interface which ${ }^{601}$ is an area of slight $\mathrm{Al}$ enrichment. This has previously ${ }_{603}^{602}$ been proposed by Nag et al. [3].

\subsection{Small Angle Neutron Scattering}

In-situ SANS was performed on a sample of Ti- $5553_{609}^{608}$ during a two step ageing heat treatment of $300{ }^{\circ} \mathrm{C} / 8 \mathrm{~h}+{ }_{610}$ $500{ }^{\circ} \mathrm{C} / 2 \mathrm{~h}$. A SANS model of disc-shaped particles fits ${ }^{611}$ the data well, and is supported by TEM and APT. The $\omega_{613}^{612}$ particles grow to a diameter of $\sim 10 \mathrm{~nm}$ and the length re-614 mains approximately constant between $\sim 4-5 \mathrm{~nm}$ during ${ }_{610}^{615}$ the $300^{\circ} \mathrm{C} / 8 \mathrm{~h}$ heat treatment.

The volume fraction of $\omega$ following $300{ }^{\circ} \mathrm{C} / 8 \mathrm{~h}$ heat618 treatment is $\sim 7 \%$, based on atom counts in the $\mathrm{APT}^{619}$ analysis. Using the APT phase composition results as in ${ }_{622}^{620}$ put to the SANS model gives a volume fraction of $\sim 10 \% .622$

\subsection{Hardness Testing}

Hardness testing shows that the $\omega$ phase increases the627 hardness of the alloy by $\sim 15 \%$, while the $\alpha$ phase increases ${ }^{628}$ the hardness by $\sim 90 \%$.

\section{Acknowledgements}

The authors would like to acknowledge funding from $\mathrm{EP}^{635}$ SRC under grant EP/H0004882/01. VAV and JC would like to $0_{637}$ acknowledge support from the EPSRC doctoral prize fellowship638 and Marie Curie fellowship respectively. This work utilizes the ${ }^{639}$ Oak Ridge National Laboratory's High Flux Isotope Reactor, ${ }_{641}^{640}$ which is sponsored by the Scientific User Facilities Division,642 Office of Basic Energy Sciences, U.S. Department of Energy.643 $\mathrm{JC}$ would like to thank R Chater for providing training in $\mathrm{FIB}^{644}$ milling and his helpful discussions. For the APT analysis, T.L. ${ }_{646}^{645}$ Martin is thanked for assistance with running samples and M.P. Moody for helpful discussions. PAJB acknowledges support from The Queen's College Oxford for experiments performed at Harvard University, USA.

\section{References}

1] Bania PJ JOM 1994;46(7):16

2 Boyer RR \& Briggs RD JMEPEG 2005;14:681

3. Nag S, Banerjee R, Srinivasan R, Hwang JY, Harper M, Fraser HL. Acta Mater 2009 57:2136

[4] Jones NG, Dashwood RJ, Dye D, Jackson M Mater Sci \& Eng A 2008;490:269

[5] Williams JC In: Jaffee RI \& Burte HM et al. eds., Ti1973 Science and Technology. Plenum Press, New York USA. 1973:14331494

[6] Lütjering G \& Williams JC Titanium. Springer-Verlag, Berlin Heidelberg New York. 2003

[7] Raghunathan SL, Stapleton AM, Dashwood RJ, Jackson M, Dye D. Acta Mater 2007 55:6861

[8] Jones NG, Dashwood, RJ. Jackson M, Dye D Acta Mater 2009; $57: 3830$

[9] Duerig TW, Williams JC. In: Boyer RR, Rosenberg HW, eds., AIME, New York, USA, 1984:19-67

[10] Nag S et al. Phy Rev Lett 2011 106:245701
11] Nag S, Banerjee R, Hwang JY, Harper M, Fraser HL. Phil Mag 2009 89(6):535

12] Nag S, Banerjee R, Fraser HL. J Mater Sci 2009;44:808

13. Bowen AW Scr Met 1971;5(8):709

14] Coakley J, Reed RC, Warwick JLW, Rahman KM, Dye D. Acta Mater 2012;60:2729

15] Stone HJ, Holden TM, Reed RC. Acta Metall 1999;47:4435

16 Ma S, Rangaswamy P, Majumdar BS. Scr Mater 2003:48:525

17 Ma S, Brown D, Bourke MAM, Daymond MR, Majumdar BS. Mater Sci Eng A 2005;399:141

[18] Daymond MR, Preuss M, Clausen B. Acta Mater 2007:55:3089

19] Preuss M, da Fonesca JQ, Grant B, Knoche E, Moat R, Daymond M. In: Reed RC, Green KA, Caron P, Gabb TP, Fahrmann MG, Huron ES, Woodard SA, eds., Superalloys 2008. TMS, PA, 405-414

[20] Dye D, Coakley J, Vorontsov VA, Stone HJ, Rogge RB. Scr Mater 2009:48:525

21] Coakley J, Dye D. Scri Mater 2012;67:435

22] Wignall GD, Littrell KC, Hetter WT, Melnichenko YB, Kailey KM, Lynn GW, Myles DA, Urban VS, Buchanan MV, Selby DL, Bulter PD J Appl Cryst 2012;45:990

[23] Miller MK. Atom Probe Tomography: Analysis at the Atomic Level, Kluwer Academic. New York, USA. 2000

[24] Gault RB, Moody MP, Cairney JM, Ringer SP. Atom Probe Microscopy, Springer. New York, USA. 2006

25] Thompson K. et al. Ultramicroscopy 2007:107:131

26. Cerezo A et al. Materials Today 2007:10(12):36

27. Kelly TF \& Larson DJ. Mater Char 2000;44:59

28 Jamieson JC Science 1963;140:72

29 Liu JP et al. Sci Rep 2013 3:2156

30] Blackburn MJ, Williams JC. Trans Met Soc AIME 1968 242:2461

[31] Pennock GM, Flower HM, West DRF. Titanium 1980: Science and Technology 1343

[32] Furuhara T, Maki T, Makino T. J Mater Proc Technol 2001 $117: 318$

33] Hickman BS J Inst Met 1968 96:330

34 Langmayr F, Fratzl P, Vogl G. Phys Rev B 1994 49(17):11759

35. Azimzadeh S, Rack HJ. Metall Mater Trans A 199829:2455

36] Prima F, Vermaut P, Texier G, Ansel D, Gloriant T. Scripta Mater 200654:645

[37] Coakley J, Vorontsov VA, Littrell KC, Heenan R, Ohnuma M, Jones NG, Dye D. J Alloy Compd 2015 623:146

[38] Heenan RK. RAL Report 1989;89

39] King SM. In: Pethrick RA, Dawkins JV, eds., Modern techniques for polymer characterisation. Wiley, Chichester, 1999:171-232

[40] Ashcroft NW, Lekner J. Phys Rev 1966;145:83 Kline SRJ. J Appl Cryst 2006;39(6):895

[41] Sears VF. Neutron News 1992;(3)3:26 